\title{
Astrocitoma pilocítico juvenil con diseminación leptomeníngea
}

\author{
Juvenile pilocytic astrocytoma with leptomeningeal dissemination
}

\author{
- Andrés Felipe Cardona ${ }^{1,2}$, Luis Eduardo Pino ${ }^{3}$, Milton Lombana ${ }^{3}$, León Darío Ortiz ${ }^{4}$, Nicolás Useche \\ 'Grupo Oncología Clínica y Traslacional, Instituto de Oncología, Fundación Santa Fe de Bogotá (Bogotá, Colombia). \\ 2Fundación para la Investigación Clínica y Molecular Aplicada del Cáncer (FICMAC) (Bogotá, Colombia); investigador asociado ONCOLGroup. \\ 'Departamento de Oncología y Hematología, Universidad Militar Nueva Granada, Hospital Militar Central (Bogotá, Colombia). \\ ${ }^{5}$ Departamento de Imágenes Diagnósticas, Sección Neurorradiología, Fundación Santa Fe de Bogotá (Bogotá, Colombia).
}

Se exponen las imágenes de un hombre de 22 años que ingresó al servicio de urgencias de la Fundación Santa Fe de Bogotá por presentar un cuadro clínico de 14 días de evolución caracterizado por cefalea global pulsátil con signos de alarma por diplopía horizontal, emesis incoercible, agitación y desorientación temporoespacial. Durante la evaluación inicial, se documentó postura tónica sin relajación de esfínteres, evento que fue muy similar al presentado en el 2001, después del cual se documentó un sangrado mesencefálico, que se interpretó extrainstitucionalmente como secundario a una alteración alterovenosa. No obstante, en el 2010, se realizó una resonancia cerebral que documentó una lesión irregular localizada en la cisterna cuadrigeminal con extensión a través del conducto de Silvio hasta el cuarto ventrículo; dicha alteración parecía originarse a nivel pineal, presentaba captación heterogénea del medio de contraste, especialmente en la periferia, y no tenía hidrocefalia obstructiva, pero sí efecto compresivo sobre el mesencéfalo. También se evidenció en el

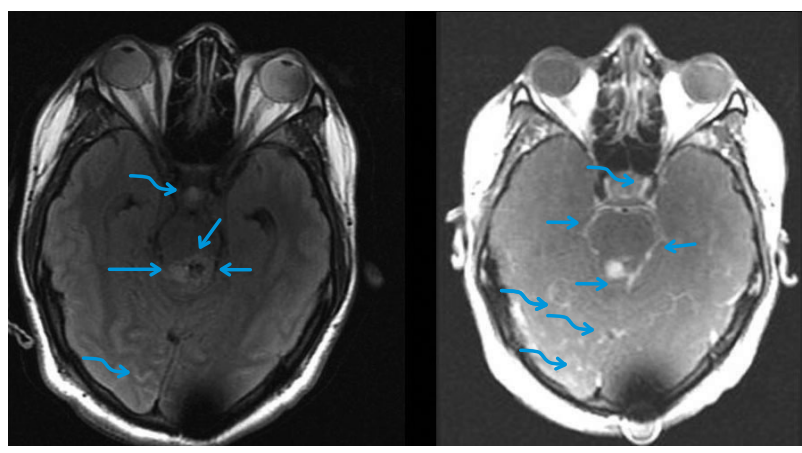

Figura 1. Los cortes axial FLAIR (derecha) y axial T1 con medio de contraste (izquierda) documentaron una alteración de la señal y realce, especialmente alrededor del acueducto y en las cisternas basales, acompañados de un nódulo neoplásico (flecha). También se identificó aumento de la señal y realce con contraste en los surcos cerebrales y en la cisterna supraselar (flechas curvas). Estos hallazgos indicaron la presencia de una diseminación leptomeníngea intracraneana e intraventricular.
FLAIR y en la secuencia T1 con medio de contraste una alteración de la señal y realce alrededor del acueducto, en las cisternas basales, en los surcos cerebrales y en la cisterna supraselar. Estos hallazgos indicaron una posible diseminación leptomeníngea e intracraneana de un tumor por establecer (figura 1).

De igual forma, se examinó la columna vertebral, encontrando metástasis en gota a nivel dorsal y lumbar (figuras 2a y 2b). Bajo la impresión de un posible tumor germinal, se decidió efectuar una biopsia, que se llevó a cabo el 15 de octubre del mismo año. La patología describió la presencia de un tumor astrocitario de bajo grado, compatible con un astrocitoma pilocítico juvenil con diseminación leptomeníngea. Durante los últimos 20 meses de observación, no se encontraron cambios clínicos, hasta julio del 2012 cuando describió mayor afectación visual en relación con el aumento de las lesiones supraselares y de las cisternas basales (figura 3) y del realce leptomeníngeo multifocal (figuras 4 y 5).

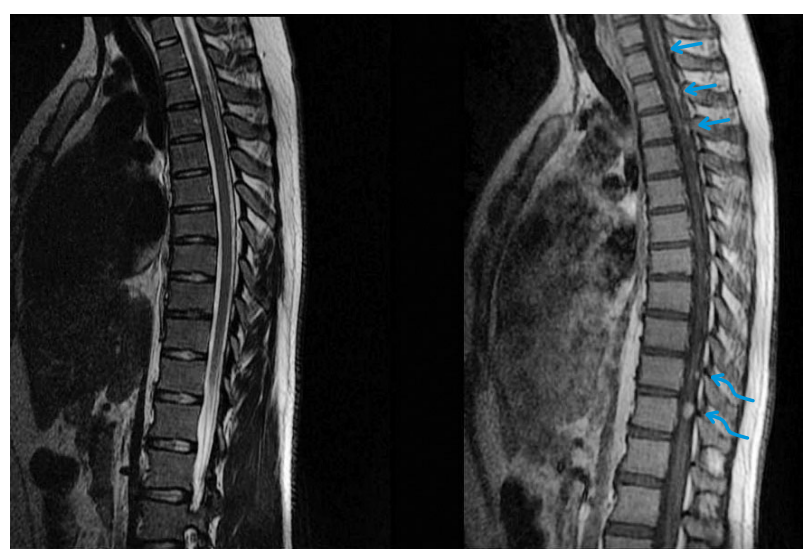

Figura 2a. Cortes sagital T2 (izquierda) y T1 con contraste (derecha) de la columna torácica. No se descarta cualquier alteración en los cuerpos vertebrales, en presencia de realce que indica diseminación leptomeníngea (flechas) y metástasis "en gota" (flecha curva). 

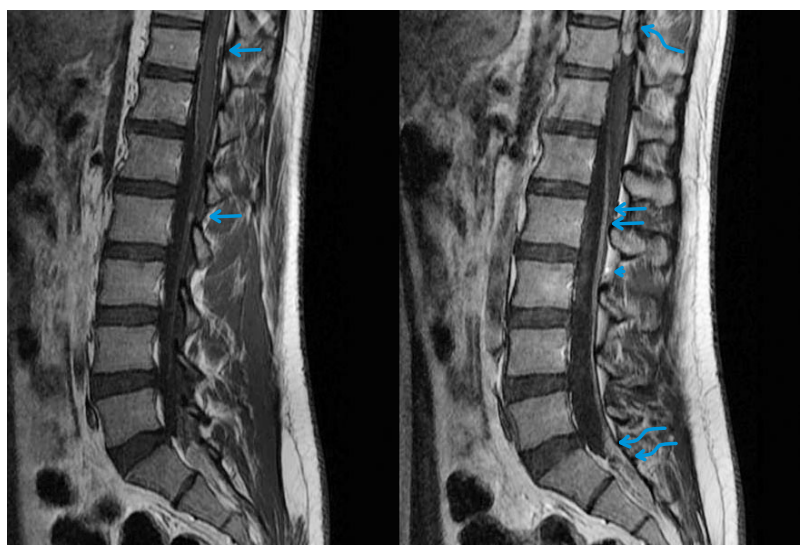

Figura $\mathbf{2 b}$. Cortes sagitales T1 con contraste de la columna lumbar. Se observan metástasis leptomeníngeas (flecha), perirradiculares (flecha doble), en el cono medular (flecha curva) y en el fondo del saco tecal (flecha curva doble).

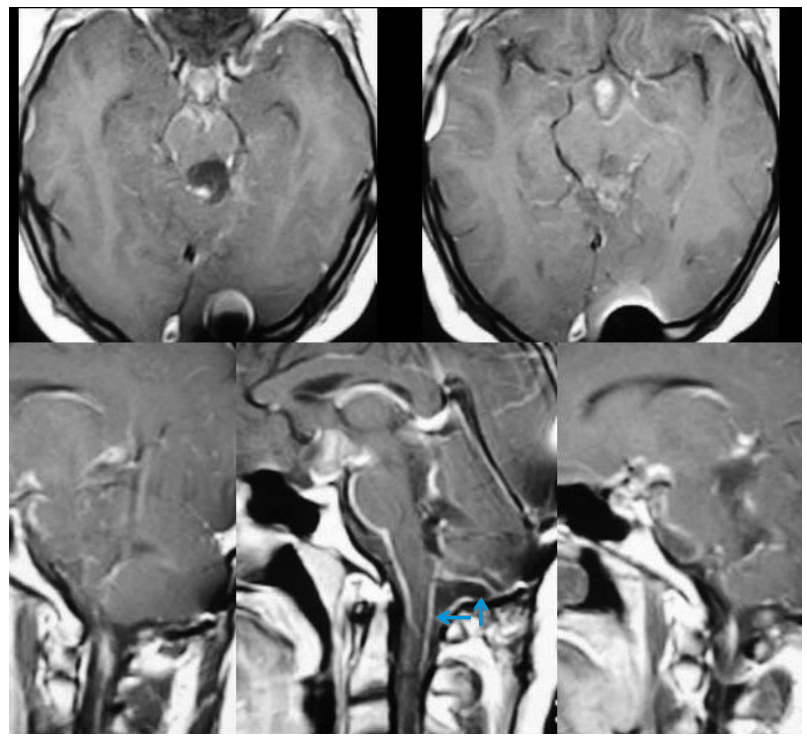

Figura 4. Cortes axiales (superiores) y sagitales en T1 con contraste (inferiores) Aumento en el realce leptomeníngeo a nivel del aspecto posterior de la médula y en el cerebelo (flechas).

De forma general, los astrocitomas pilocíticos tienen un crecimiento lento y suelen presentarse con mayor frecuencia en los niños y adultos jóvenes; su localización más común es en los hemisferios cerebelosos y en la vecindad del tercer ventrículo, pero con alguna frecuencia se documentan en los hemisferios cerebrales' ${ }^{1}$. Raramente sufren una transformación maligna, evento que ocurre al menos en el $5 \%$ de los casos y que suele suceder después de la radioterapia en el 60 al $80 \%$ de los tumores de patrón esporádico; se demuestra una duplicación en tándem del cromosoma 7q34 que se asocia con el gen de fusión BRAF-KIAA². La diseminación leptomeníngea es rara, y la supervivencia reportada luego de este evento es inferior a 65 meses; no

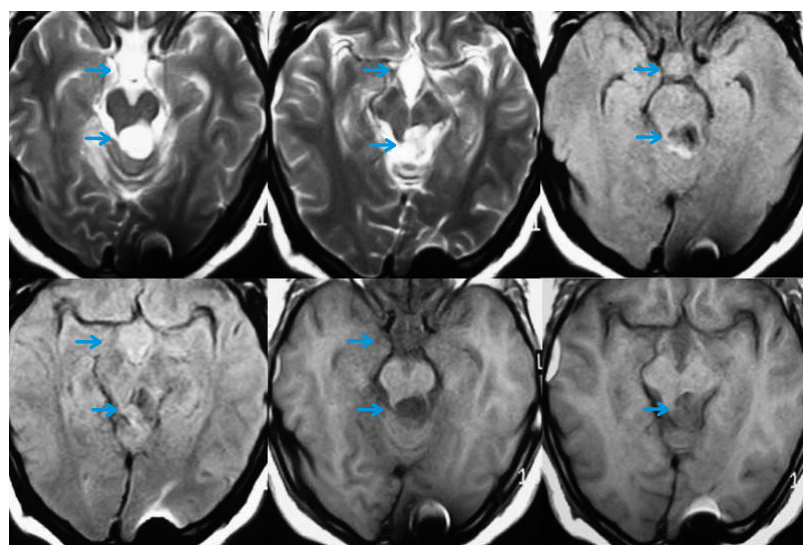

Figura 3. Cortes axial T2 y FLAIR (superiores) y axial T1 simple (inferiores). Se observa leve aumento en la alteración de la señal y en el tamaño de las lesiones supraselares y en las cisternas basales (flechas).

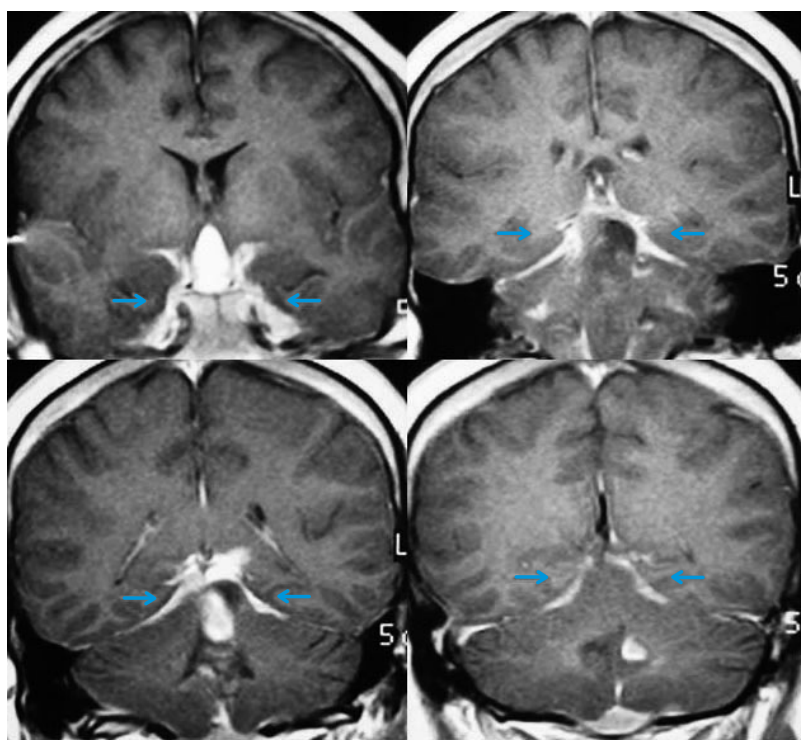

Figura 5. Cortes coronales en T1 con contraste. Aumento en el realce leptomeníngeo en el cavum de Meckel y en el tentorio (flechas).

obstante, un segmento de los pacientes se beneficia de la administración de quimioterapia, utilizando agentes como la temozolamida?

\section{Referencias}

1. Schneider JH Jr, Raffel C, McComb JG. Benign cerebellar astrocytomas of childhood. Neurosurgery. 1992;30(1):58-62.

2. Horbinski C, Hamilton RL, Nikiforov Y, Pollack IF. Association of molecular alterations, including BRAF, with biology and outcome in pilocytic astrocytomas. Acta Neuropathol. 2010;119(5):641-9.

3. Mazloom A, Hodges JC, Teh BS, Chintagumpala M, Paulino AC. Outcome of patients with pilocytic astrocytoma and leptomeningeal dissemination. Int J Radiat Oncol Biol Phys. $2012 ; 84(2): 350-4$ 